\title{
Rwanda struggles to treat its burden of blindness
}

$\mathrm{M}$ en, women, and children with bloodshot eyes, swollen faces and rashes sit in a dimly-lit waiting room at the Kanombe Military Hospital eye clinic in Rwanda. A boy who may have river blindness fidgets. An elderly man on make-shift crutches relies on a nurse to guide him.

None are at the hospital for a casual eye exam. With only one ophthalmologist for every one million Rwandans, trips to the government-subsidized eye clinic seem reserved for patients with serious eye conditions, infections or near blindness.

There are about 80000 Rwandans who are legally blind in both eyes, says Dr. John Nkurikiye, an ophthalmologist at the state-run King Faisal Hospital in the capital city of Kigali. He estimates $75 \%$ of those people could be cured or have their eyesight improved with appropriate care. Having more specialists capable of cataract removal would have a particularly beneficial effect, he adds.

"The main problem is that these people are mostly based in rural areas people who cannot afford to come to Kigali or big hospitals," says Nkurikiye.

To redress that, the government has unveiled a National Plan for Eliminating Needless Blindness. When fully implemented, it will see at least one ophthalmologist appointed to each of nine prescribed geographic regions, with a referral network of lower-level eye care professionals in surrounding areas.

But the country has a long way to go.

"We have about nine ophthalmologists and all nine work in two provinces - Kigali and the southern province," explains Nkurikiye. Midlevel workers at district hospitals diagnose and treat certain eye problems such as refractive errors, trachoma and onchocerciasis (river blindness), while referring other patients to ophthalmologists for more complicated procedures such as corneal transplantation or cataract surgery.

One weekend per month, Nkurikiye and other ophthalmologists volunteer to

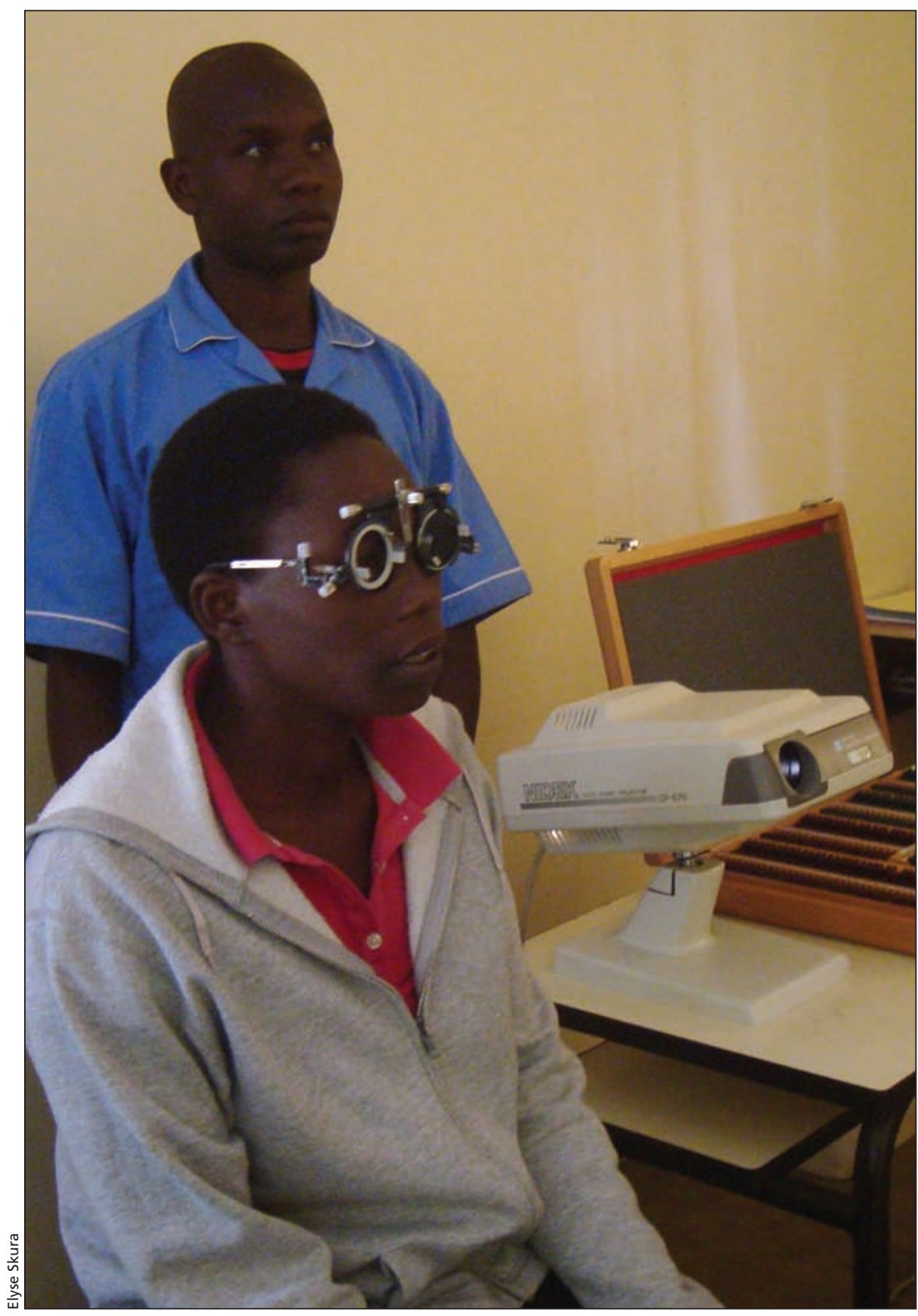

A woman has her eyes tested at the Kanombe Military Hospital eye clinic in Rwanda.

perform surgeries in rural health centres. "It's easier for the surgeon to move to the community than for the community to move to the surgeon," he says.

Partial blindness can be particularly debilitating for villagers whose livelihood depends on manual labour, Nkurikiye says. "If you talk to them, they'll tell you: 'For the last three or four years I wasn't able to do anything. I needed somebody to help me, somebody to feed me, somebody to take me out'. But once you do the operation, the following day their life changes completely because they can now see again. They can resume their professional 
activities. They can go back to the field and work."

The desperation is evident even in those who can travel to health clinics, like the one at Kanombe.

Nineteen-year-old Vistine Ndayisaba says through a translator that "I feel like there is no hope for me." She has been partially blind since she was a child, but only started to receive treatment for what appeared to be some form of eye infection two years ago.

Christophe Barirwanda, an elderly man on crutches, is asked to make out letters projected on a wall. But when he is unable to identify an "E" that is nearly six inches high, attendants resort to standing a few feet away, holding up fingers, and asking how many of them he can see.

"I've had it since 1994, and as the years pass by I get more blind," he says through an interpreter. "I can't see objects that are right in front of me and I also can't see people's faces."

Second Lieutenant Fidele Kaisire, a clinic officer at the hospital, says the facility sees between 20 and 40 patients per day, most of whom are easily treated. The remainder are referred to Nkurikiye.

That referral system saves a lot of time, says Nkurikiye. Before it was introduced, people would arrive for all manner of eye problems. "If [patients] had something to do with allergies, like itchy eyes, [they] would go to the specialist," he says. If minor problems are treated at clinics, "then we can have time to do more surgery."

The ultimate goal is to perform 1500 operations per million Rwandans per year. That is what's needed to deal with Rwanda's burden of blindness, says Nkurikiye. "Today we are doing about 300."

One of the biggest obstacles is the absence of a program to train specialists. Although the government is working on a program, for now, the country sends students to South Africa and other African countries.

Such specialist shortages are endemic, says Dr. Joseph Nzabamwita, who was trained in Uganda before opening a private clinic in Kigali.

"There is a shortage. There is a shortage not in ophthalmology only," he says. "In education, there is a shortage. In medicine, there is a shortage. In everything, there is a shortage."

Nzabamwita says the government's Plan for Eliminating Needless Blindness has helped. "Things are changing with time," he explains. "There was a time when people had to go to Butare [a two-and-a-half-hour bus trip] from here for an eye exam. That was for the whole country. They had to be there at midnight in order to be seen the next day."

Nzabamwita also hopes the plan will make it easier for patients to receive care in outlying regions.

But to achieve the ambitious goals of making Rwanda a leader in eye care by 2020 (www.cdf.gov.rw/documents $\% 20$ library/important\%20docs/Vision _2020.pdf), more money and logistical support will be needed.

That may be problematic as Nkurikye notes that Rwanda faces a raft of other pressing health priorities, such as malaria and AIDS. - Elyse Skura, Kigali, Rwanda

CMAJ 2011. DOI:10.1503/cmaj.109-3740 